\title{
Genetic Investigation of BPT-5204 Derived Rice (Oryza sativa L.) Genotypes for Yield and Yield Attributed Characters under Direct Seeded Condition
}

\author{
Basavaraj S. Kovi $^{1}$, J.R. Diwan ${ }^{1 *}$, K. Mahantashivayogayya ${ }^{2}$, R. Lokesha ${ }^{1}$, \\ T.C. Suma ${ }^{3}$ and M.S. Ramesha ${ }^{4}$ \\ ${ }^{1}$ Department of Genetics and Plant Breeding, University of Agricultural Sciences, \\ Raichur-584104, Karnataka, India \\ ${ }^{2}$ AICRP on Rice Breeding, ARS, Gangavathi, Karnataka, India \\ ${ }^{3}$ Department of Crop Physiology, University of Agricultural Sciences, \\ Raichur-584104, Karnataka, India \\ ${ }^{4}$ IRRI lab Head South East Asia, International Crops Research Institute for Semi-Arid Tropics, \\ Patancheru, Hyderabad- 502324, Telangana, India \\ *Corresponding author
}

\section{A B S T R A C T}

An experiment was carried out to estimate the variability parameters for yield and yield attributed characters in 40 rice genotypes which are derived in the background of BPT-

\begin{tabular}{|c|}
\hline Keywords \\
\hline $\begin{array}{l}\text { Genetic advance, } \\
\text { Genetic variability, } \\
\text { Direct seeded rice } \\
\text { (Oryza sativa L.), } \\
\text { BPT-5204 derived } \\
\text { genotypes. }\end{array}$ \\
\hline Article Info \\
\hline $\begin{array}{l}\text { Accepted: } \\
17 \text { October } 2017 \\
\text { Available Online: } \\
10 \text { December } 2017\end{array}$ \\
\hline
\end{tabular}
5204. Analysis of variance (ANOVA) revealed the existence of significant differences among genotypes for all traits studied. Genotypic coefficient of variation played a major role for the expression of the traits and ranged from 2.63 (Days to 50\% flowering) to 47.32 (Un-filled grain number per panicle). The difference between values of phenotypic and genotypic variances along with their corresponding PCV and GCV for yield related traits was insignificant indicating low sensitivity to environment consequently higher role of genetic factors influencing the trait expression. Heritability ranged from 34.33 (Days to $50 \%$ flowering) to 95.00 (Un-filled grain number per panicle). High heritability coupled with high genetic advance as percent of mean was found for shoot biomass (80.51 and 64.72), root biomass (84.52 and 64.85), grain filling duration (80.83 and 24.39), tiller number per plant (91.43 and 49.47), panicle number per plant (85.42 and 50.70), flag leaf length (79.52 and 25.56) and test weight (64.63 and 37.87) indicated that high response to selection for these traits. On the basis of mean performance, the highest grain yield per plant was observed for the genotype 16KDSBPT-8 (38.59 g) and was found $10.37 \%$ superior in grain yield than BPT-5204 (28.23 g) followed by 16KDSBPT-21 (38.02 g) and 16KDSBPT-27 (37.79 g) which found 9.79\% and 9.56\% superior in yield than BPT-5204.

\section{Introduction}

Rice is a self-pollinated cereal crop belonging to the family Poaceae under the order Poales and class monocotyledon with chromosome number $2 \mathrm{n}=24$. The genus Oryza consists of 24 species out of which two are cultivated viz. Asian rice $(O$. sativa, $2 \mathrm{n}=24=\mathrm{AA})$ and
African rice $(O$. glaberrima, $2 \mathrm{n}=24=\mathrm{AA})$ and remaining 22 are wild species $(2 \mathrm{n}=24,48)$. In 2011, genetic evidence showed that all forms of Asian rice, both indica and japonica, sprang from a single domestication that occurred 8,200-13,500 years ago in China 
from the wild rice Oryza rufipogon (Molina et al., 2011). A study in 2012, through a map of rice genome, indicated that the domestication of rice occurred in the Pearl River valley region of China (Huang et al., 2012).

Rice is income generating crop and major contributor for food security and occupies a pivotal place in Indian Agriculture and it contributes for 15 per cent of annual GDP and provides 43 per cent calorie requirement for more than 70 per cent of Indians (Sumanth et al., 2017). Globally, Rice is cultivated over an area of 158.84 million hectares with the production of 471.72 million tons during 2015-16 (Anon, 2017). Among rice growing regions, Asia is the largest producer (144.25 million tons) and India is the second largest producers of rice in world after China, accounting for $22 \%$ of World's rice production. Rice being India's pre-eminent crop, covering an area of $43.50 \mathrm{mha}$. and production of $104.41 \mathrm{mt}$ with the productivity of $2400 \mathrm{Kg} / \mathrm{ha}$ (Anon, 2016).

The main method of rice establishment in the country is puddle transplanting. But this production system is water, labour and energy intensive. Nowadays, these resources are becoming increasingly scarce, so this system is becoming less profitable. All these factors played an important role to increase the demand for shifting from puddled transplanting to direct seeding of rice in irrigated rice ecosystems. Direct Seeded Rice (DSR) refers to the process of establishing a rice crop from seeds sown in the field rather than by transplanting seedlings from the nursery. This method is mostly adopted in rainfed uplands and lowlands where rainfall is uncertain, the topography is undulating and fields are unbunded. Actually, direct seeding is not a new concept; rather it is the oldest method of rice establishment. DSR was the most common method before the 1950s (Pandey and Velasco 2005).
The success of breeding program depends upon the quantum of genetic variability available for exploitation and the extent to which the desirable characters are heritable (Tiwari et al., 2011). Variability refers to the presence of differences among the individuals of plant population. Variation results due to difference either in genetic constitution of the individual of a plant population or in environment, they have grown. Critical estimate of nature and magnitude of genetic variability is a prerequisite for any crop improvement programme which provides base for the breeders to exercise selection. The variability observed in any population could be due to the genetic and environmental factors and also due to the interaction between these factors (Sumanth et al., 2017). The present investigation was carried out to estimate the variability existed in the genetic material under study.

\section{Materials and Methods}

The experimental material for the present investigation consists of 40 (including 10 checks) rice genotypes which are in the background of BPT-5204 (Table 1). The genotypes were supplied from IRRI-India (ICRISAT). These genotypes were grown in randomized block design (RBD) with two replications during kharif- 2016 at Agricultural Research Station Gangavathi under University of Agricultural Sciences, Raichur. The seeds were sown at $20 \mathrm{~cm} \mathrm{x} 15$ $\mathrm{cm}$ spacing and soon after irrigation was applied to ensure uniform germination. Five representative plants for each genotype in each replication were randomly selected to record observations on field emergence, shoot biomass (at 30 Days After Sowing), root biomass (at 30 DAS), plant biomass dry weight (at harvesting), plant height $(\mathrm{cm})$, flag leaf length $(\mathrm{cm})$, tiller number per plant, panicle number per plant, panicle length, filled grains per panicle, unfilled grains per 
panicle, test weight, and grain yield per plant (g). Days to $50 \%$ flowering and grain filling duration were computed on plot basis and data was subjected to statistical analysis.

The variability was estimated as per procedure for analysis of variance suggested by Panse and Sukhatme (1967). PCV and GCV were calculated by the formula given by Burton (1952) heritability in broad sense $\left(\mathrm{h}_{\mathrm{bs}}{ }^{2}\right)$ by Burton and De Vane (1953) and genetic advance i.e. the expected genetic gain were calculated by using the procedure given by Johnson et al., (1955).

\section{Results and Discussion}

Genetic variability in any crop is pre-requisite for selection of superior genotypes over the existing cultivars. The analysis of variance for different characters indicated the existence of highly significant differences for all the characters under study at $1 \%$ level of significance suggesting each and every genotype are genetically divergent from each other and there is ample scope for selection of characters from these diverse sources for yield and its components (Table 2). These findings were in accordance with the findings of Sumanth et al., (2017) and Srujana et al., (2017). Based on mean yield the percent superiority of the genotypes ranged from $15.74 \%$ (GNV-10-89) to $10.37 \%$ (16KDSBPT-8) and mean yield of all 40 genotypes along with percent superiority or inferiority over the check BPT-5204 is given in Table 1.

In the present study phenotypic variance $(\mathrm{Vp})$ and phenotypic coefficient of variation (PCV) were higher than their corresponding genotypic variance (Vg) and genotypic coefficient of variation (GCV) for field emergence, shoot biomass, root biomass, dry weight of plant biomass, days to $50 \%$ flowering, filled grain number per panicle, test weight, panicle weight and yield per plant (Table 3 and Fig. 1) indicated that the expression of these characters was influenced by environment, whereas the difference between values of phenotypic and genotypic variances along with their corresponding PCV and GCV for grain filling duration, panicle length, tiller number per plant, panicle number per plant, unfilled grain number per panicle, plant height, panicle and yield was insignificant indicated low sensitivity to environment consequently higher role of genetic factors influencing the trait expression and the offsprings of these genotypes will be like their parents because there are no visible environmental effects on the expression of these characters.

The genes expressed in each of these traits may be under the control of homozygous alleles. The characters with almost equal value of $\mathrm{Vp}$ and $\mathrm{Vg}$ coupled with their corresponding PCV and GCV can be considered as stable. Similar findings were reported by Roy et al., (2015). The estimates of genotypic variability ( $\mathrm{Vg}$ ) and GCV being the most important parameters, helps in the measurement of the contribution of the genotype to the expression of a particular character and gives clue to compare the genetic variability for different characters. This gives scope for selection of plants which contribute for better yield contributing traits. Srujana et al., (2017) reported high to moderate estimates of $\mathrm{GCV}$ and $\mathrm{PCV}$ for grain yield per hill, harvest index, spikelets per panicle, tillers per hill, flag leaf length, panicles per hill.

Results of the present study are also supported by the results obtained by Vaithiyalingan and Nadarajan (2006); and Vivek et al., (2004) also reported high phenotypic coefficient of variation values for number of spikelets per panicle, number of panicles per hill and grain yield per hill. 


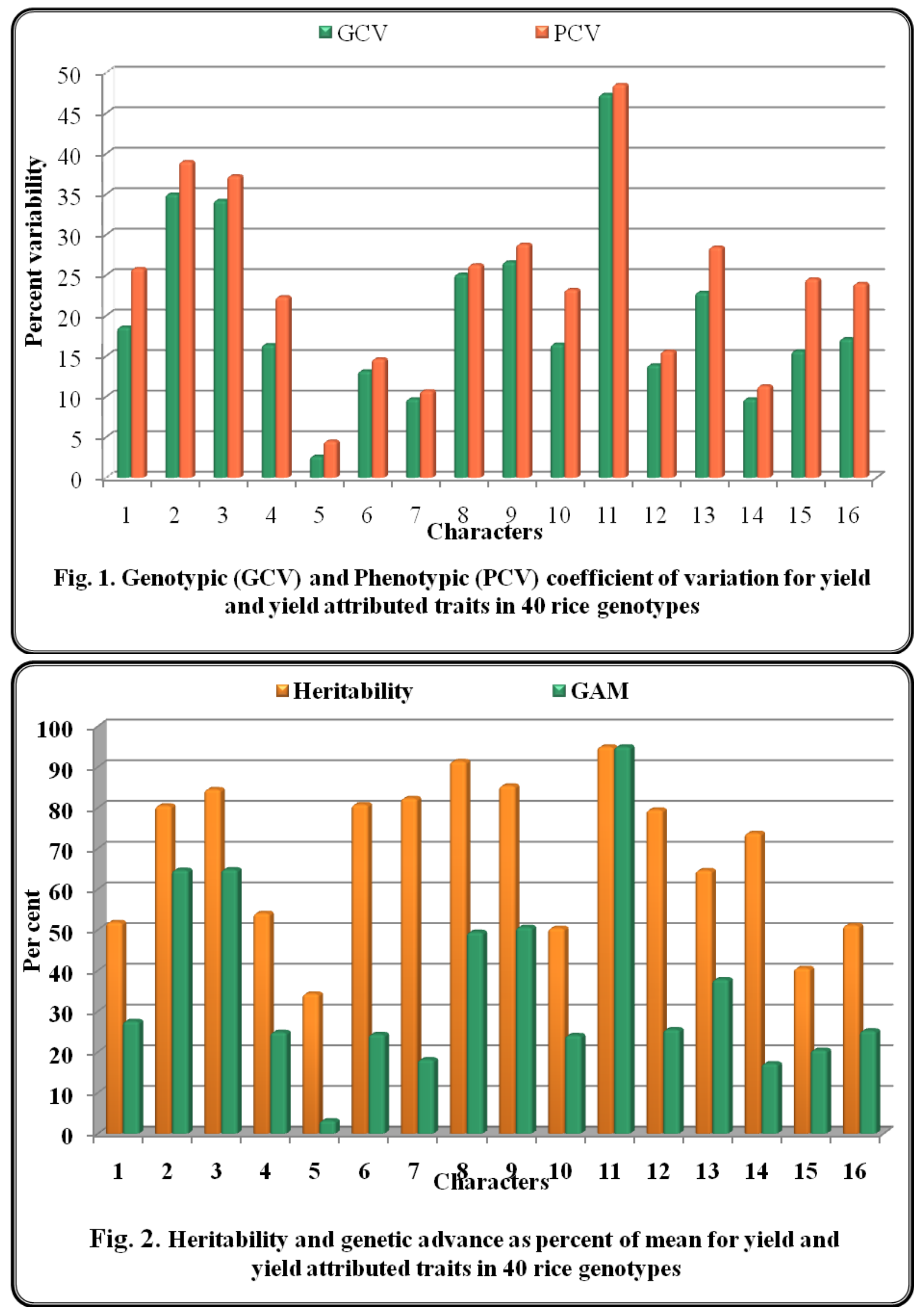


Table.1 List of 40 rice genotypes (including 10 checks) used in the present study with their mean of grain yield per plant

\begin{tabular}{|c|c|c|c|c|c|c|c|}
\hline Sl. No & Entry name & Mean yield & PI & SI. No & Entry name & Mean yield & PI \\
\hline 1 & 16KDSBPT-4 & 34.47 & 6.24 & 21 & 16KDSBPT-22 & 36.33 & 8.10 \\
\hline 2 & 16KDSBPT-23 & 35.45 & 7.22 & 22 & 16KDSBPT-21 & 38.02 & 9.79 \\
\hline 3 & 16KDSBPT-2 & 36.42 & 8.19 & 23 & 16KDSBPT-26 & 33.15 & 4.92 \\
\hline 4 & 16KDSBPT-15 & 32.55 & 4.32 & 24 & 16KDSBPT-3 & 35.48 & 7.25 \\
\hline 5 & 16KDSBPT-6 & 34.28 & 6.05 & 25 & 16KDSBPT-8 & 38.60 & 10.37 \\
\hline 6 & 16KDSBPT-14 & 31.63 & 3.40 & 26 & 16KDSBPT-5 & 32.92 & 4.69 \\
\hline 7 & 16KDSBPT-28 & 36.21 & 7.98 & 27 & 16KDSBPT-9 & 29.89 & 1.66 \\
\hline 8 & 16KDSBPT-17 & 29.92 & 1.69 & 28 & 16KDSBPT-7 & 31.87 & 3.64 \\
\hline 9 & 16KDSBPT-30 & 35.53 & 7.30 & 29 & 16KDSBPT-16 & 35.56 & 7.33 \\
\hline 10 & 16KDSBPT-20 & 24.80 & -3.43 & 30 & 16KDSBPT-1 & 34.16 & 5.93 \\
\hline 11 & $\begin{array}{l}\text { 16KDSBPT-31 } \\
{[\mathrm{BPT}-5204(\mathrm{C})]}\end{array}$ & 28.23 & 0.00 & 31 & $\begin{array}{l}\text { 16KDSBPT-32 } \\
\text { Gangavathi Sona (C) }\end{array}$ & 36.27 & 8.04 \\
\hline 12 & 16KDSBPT-12 & 22.27 & -5.96 & 32 & 16KDSBPT-25 & 31.59 & 3.36 \\
\hline 13 & 16KDSBPT-11 & 34.73 & 6.50 & 33 & SIRI-1253 (C) & 28.14 & -0.09 \\
\hline 14 & 16KDSBPT-19 & 15.95 & -12.28 & 34 & IET-22066 (C) & 30.84 & 2.61 \\
\hline 15 & 16KDSBPT-13 & 32.95 & 4.72 & 35 & GNV14-96-1 (C) & 12.49 & -15.74 \\
\hline 16 & 16KDSBPT-27 & 37.79 & 9.56 & 36 & IET-19251 (C) & 22.28 & -5.95 \\
\hline 17 & 16KDSBPT-10 & 34.67 & 6.44 & 37 & IR14K10214 (C) & 18.72 & -9.51 \\
\hline 18 & 16KDSBPT-29 & 34.18 & 5.95 & 38 & IR14K10197 (C) & 31.37 & 3.14 \\
\hline 19 & 16KDSBPT-18 & 33.57 & 5.34 & 39 & RNR-15048 (C) & 25.13 & -3.10 \\
\hline 20 & 16KDSBPT-24 & 36.70 & 8.47 & 40 & GNV-10-89 (C) & 16.99 & -11.24 \\
\hline
\end{tabular}

$\mathrm{C}$ in the parenthesis indicates Check, PI is \% Increase of yield over check BPT-5204. 
Table.3 Estimates of mean and other genetic parameters for different yield and yield attributing characters in rice genotypes

\begin{tabular}{|c|c|c|c|c|c|c|c|c|c|}
\hline \multirow{2}{*}{ Sl. No. } & \multirow{2}{*}{ Character } & \multirow{2}{*}{ Mean } & \multicolumn{2}{|c|}{ Variances } & \multicolumn{2}{|c|}{$\begin{array}{c}\text { Coefficient of } \\
\text { variation } \%\end{array}$} & \multirow{2}{*}{$\begin{array}{c}\mathbf{h}^{2} \text { bs } \\
(\%)\end{array}$} & \multirow{2}{*}{ GA } & \multirow{2}{*}{$\begin{array}{c}\text { GAM } \\
(\%)\end{array}$} \\
\hline & & & Vg & $\mathbf{V p}$ & GCV & PCV & & & \\
\hline 1 & Field emergence & 19.88 & 13.65 & 26.32 & 18.59 & 25.81 & 51.88 & 5.48 & 27.59 \\
\hline 2 & Shoot biomass (30DAS) & 234.91 & 6764.60 & 8402.40 & 35.01 & 39.02 & 80.51 & 152.02 & 64.72 \\
\hline 3 & Root biomass (30DAS) & 163.35 & 3128.90 & 3701.80 & 34.24 & 37.25 & 84.52 & 105.94 & 64.85 \\
\hline 4 & Plant biomass dry weight & 21.01 & 11.91 & 22.00 & 16.42 & 22.32 & 54.12 & 5.23 & 24.89 \\
\hline 5 & Days to $50 \%$ flowering & 91.61 & 5.82 & 16.96 & 2.63 & 4.50 & 34.33 & 2.91 & 3.18 \\
\hline 6 & Grain filling duration & 31.39 & 17.08 & 21.13 & 13.17 & 14.65 & 80.83 & 7.66 & 24.39 \\
\hline 7 & Panicle length & 21.73 & 4.46 & 5.42 & 9.72 & 10.71 & 82.35 & 3.95 & 18.17 \\
\hline 8 & Tiller number per plant & 12.71 & 10.19 & 11.15 & 25.11 & 26.27 & 91.43 & 6.29 & 49.47 \\
\hline 9 & Panicle number per plant & 11.61 & 9.55 & 11.18 & 26.63 & 28.81 & 85.42 & 5.88 & 50.70 \\
\hline 10 & Filled grain number per panicle & 143.81 & 561.89 & 1113.80 & 16.48 & 23.21 & 50.45 & 34.68 & 24.12 \\
\hline 11 & $\begin{array}{l}\text { Un-filled grain number per } \\
\text { panicle }\end{array}$ & 19.72 & 87.11 & 91.70 & 47.32 & 48.55 & 95.00 & 18.74 & 95.01 \\
\hline 12 & Flag leaf length & 22.08 & 9.44 & 11.87 & 13.91 & 15.60 & 79.52 & 5.64 & 25.56 \\
\hline 13 & Test weight & 18.26 & 17.44 & 26.98 & 22.87 & 28.45 & 64.63 & 6.92 & 37.87 \\
\hline 14 & Plant height & 90.18 & 76.78 & 104.05 & 9.72 & 11.31 & 73.79 & 15.51 & 17.19 \\
\hline 15 & Panicle weight & 2.85 & 0.20 & 0.49 & 15.63 & 24.53 & 40.60 & 0.58 & 20.51 \\
\hline 16 & Grain yield per plant & 31.05 & 28.32 & 55.36 & 17.14 & 23.96 & 51.16 & 7.84 & 25.25 \\
\hline
\end{tabular}

Vg: Genotypic Variance, Vp: Phenotypic variance, $h^{2}$ bs: Broad sense heritability, GAM: genetic advance as percent of mean. 
Table.2 ANOVA for different yield and yield attributing characters in rice genotypes

\begin{tabular}{|l|c|c|c|c|}
\hline \multirow{2}{*}{\multicolumn{1}{|c|}{ Source of variation }} & \multicolumn{3}{c|}{ Mean sum squares } & \\
\cline { 2 - 5 } & Replication & Treatments & Error & CV \\
\hline Degrees of freedom (d.f) & 1.00 & 39.00 & 39.00 & \\
\hline Field emergence & 16.20 & $39.97 * *$ & 12.66 & 17.90 \\
\hline Shoot biomass (30DAS) & 1833.61 & $15167.00^{* *}$ & 1637.79 & 17.23 \\
\hline Root biomass (30DAS) & 1548.80 & $6830.62^{* *}$ & 572.90 & 14.65 \\
\hline Plant biomass dry weight & 2.87 & $33.90^{* *}$ & 10.09 & 15.12 \\
\hline Days to 50\% flowering & 0.11 & $22.78^{* *}$ & 11.14 & 3.64 \\
\hline Grain filling duration & 10.51 & $38.22^{* *}$ & 4.05 & 6.41 \\
\hline Panicle length & 1.95 & $9.89^{*}$ & 0.96 & 4.50 \\
\hline Tiller number per plant & 0.01 & $21.34 * *$ & 0.96 & 7.69 \\
\hline Panicle number per plant & 2.38 & $20.73^{* *}$ & 1.63 & 11.00 \\
\hline Filled grain number per panicle & 36.99 & $1675.74 * *$ & 551.95 & 16.34 \\
\hline Un-filled grain number per panicle & 2.70 & $178.82^{* *}$ & 4.59 & 10.86 \\
\hline Flag leaf length & 0.26 & $21.31^{* *}$ & 2.43 & 7.06 \\
\hline Test weight & 0.65 & $44.42^{* *}$ & 9.54 & 16.92 \\
\hline Plant height & 0.10 & $180.82^{* *}$ & 27.27 & 5.79 \\
\hline Panicle weight & 0.11 & $0.68^{* *}$ & 0.29 & 18.90 \\
\hline Grain yield per plant & 19.36 & $83.68^{* *}$ & 27.04 & 16.75 \\
\hline
\end{tabular}

** indicates significance at $1 \%$ level of significance

Heritability is a measure of the extent of phenotypic variation caused by the action of genes. For making effective improvement in the character for which selection was practiced, heritability has been adopted by large number of workers as a reliable indicator. Heritability in broad sense includes both fixable (additive) and non-fixable (dominant and epistatic) variances and also provides a good indication about the repeatability of the traits. The proportion of genetic variability which was transmitted from parents to offspring is reflected by heritability. According to Lush (1949) heritability in broad sense is the ratio of total genotypic variance to phenotypic variance, expressed in percentage. The estimates of heritability are more advantageous when expressed in terms of genetic advance. High heritability estimates (above 60\%) along with high genetic advance as percent of mean (above 20\%) would be helpful in predicting genetic gain under selection than heritability estimates alone. Johnson et al., (1955) suggested that heritability and genetic advance when calculated together would prove more useful in predicting the resultant effect of selection on phenotypic expression, without genetic advance the estimates of heritability will not be of practical value and emphasized the concurrent use of genetic advance along with heritability. In the present study high heritability coupled with high genetic advance as percent of mean was found for shoot biomass (80.51 and 64.72), root biomass (84.52 and 64.85), grain filling duration (80.83 and 24.39), panicle length (82.35 and 18.17), tiller number per plant (91.43 and 49.47), panicle number per plant (85.42 and 50.70), flag leaf length (79.52 and 25.56), test weight (64.63 and 37.87) and plant height (73.79 and 17.19) given in Table 3 and graphically represented in Figure 2 indicated that high response to selection for these traits, similar results of high heritability were recorded by Bhandarkar et al., (2002) 
for plant height and high genetic advance values have explained the predominance of additive gene action and selection for these traits can be carried in early generations. Therefore, selection of genotypes based on these characters would be more effective to be successful for target plant selection and these findings are in accordance with the findings of Rashid et al., (2017).On the contrary low to moderate heritability coupled with low to moderate genetic advance values were recorded for field emergence (51.88 and 27.59), plant biomass dry weight (54.12 and 24.89 ), days to $50 \%$ flowering (34.33 and $3.18)$, filled grain number per panicle $(50.45$ and 24.12), panicle weight (40.60 and 20.51) and yield per plant (51.16 and 25.25) indicated non-additive gene effects; suggesting that these characters could be improved by developing hybrid varieties. These results are supported by the findings of Ogunbayo et al., (2014).

The present investigation, included 40 genotypes of rice, was carried out in order to study the nature and amount of variability, heritability and genetic advance for 16 quantitative characters. High heritability coupled with high genetic advance as percent mean were observed for the traits like shoot biomass, root biomass, grain filling duration, panicle length, tiller number per hill, panicle number, flag leaf length and plant height and hence we can use these traits for further improvement of the genotypes for yield and yield attributing characters.

On the basis of mean performance, the highest grain yield per plant was observed for the genotype 16KDSBPT-8 (38.59 g) and was found $10.37 \%$ superior in grain yield than BPT-5204 (28.23 g) followed by 16KDSBPT$21(38.02 \mathrm{~g})$ and 16KDSBPT-27 (37.79 g) which found $9.79 \%$ and $9.56 \%$ superior in yield than BPT-5204 and these genotypes can be used as varieties after testing in multiplications for their stable performance or they can be used as parents in hybridization programme.

\section{References}

Anonymous, 2016, Indiastat https://www. indiastat.com/table/agriculture/2/rice/17 194/1004419/data.aspx

Anonymous, 2017, USDA. https://apps.fas. usda.gov/psdonline/circulars/productio $n . p d f$

Bhandarkar, S., Ravindra, V., Arvind, K., Verma, R. and Kumar, A., 2002, Genetic variability and correlation analysis in early duration rice. Plant Archives, 2(1): 95-98.

Burton, G. W., 1952, Quantitative inheritance in grasses. Proc. VI. Institute Grassland Congr, 1:155-157.

Burton, G. W., De Vane, E. H., 1953, Estimating heritability in tall fesscusce from replicated clone natural materials. Agronomy Journal. 45:171-181.

Huang, X., Kurata, N., Wang, Z. X., Wang, A., Zhao, Q., Zhao, Y. and Lu, Y., 2012, A map of rice genome variation reveals the origin of cultivated rice. Nature, 490(7421): 497.

Johnson, H. W., Robinson, H. F. and Comstock, R. E., 1955, Estimates of genetic and environmental variability in Soybean. Agron J. 47:314-318.

Lush, J. L., 1949, Inter-se, correlation and regression of characters. Proceeding of American Society of Animal Production.33: 293-301.

Molina, J., Sikora, M., Garud, N., Flowers, J. M., Rubinstein, S., Reynolds, A. and Boyko, A. R., 2011, Molecular evidence for a single evolutionary origin of domesticated rice. Proceedings of the National Academy of Sciences, 108(20): 8351-8356.

Ogunbayo, S.A., Sié, M., Ojo, D.K, Sanni, K.A., Akinwale, M.G., Toulou, B., 
Shittu, A., Idehen, E.O., Popoola, A.R., Daniel, I.O. and Gregoria, G.B., 2014, Genetic variation and heritability of yield and related traits in promising rice genotypes (Oryza sativa L.). J. Plant Breed. Crop Sci. 6(11): 153-159.

Pandey, S. and Velasco, L., 2005, Trends in crop establishment methods in Asia and research issues. Rice is life: Scientific perspectives for the 21st century, 178181.

Panse, V. G. and Shukhatme, P. V., 1967, Statistical Methods for agricultural workers. $2^{\text {nd }}$ edition, ICAR, New Delhi: 152-157.

Rashid, M. M., Nuruzzaman, M., Hassan, L. and Begum, S. N., (2017), Genetic variability analysis for various yield attributing traits in rice genotypes. Journal of the Bangladesh Agricultural University, 15(1): 15-19.

Roy, R. K., Majumder, R., Sultana, S., Hoque, E. and Ali, M. S., (2015), Genetic variability, correlation and path coefficient analysis for yield and yield components in transplant aman rice (Oryza sativa L.). Bangladesh Journal of Botany. 44: 529-535.

Srujana, G., Suresh, B. G., Lavanya, G. R.,
Ram, B. J. and Sumanth, V. 2017, Studies on Genetic Variability, Heritability and Genetic advance for yield and quality components in rice (Oryza sativa L.). Journal of Pharmacognosy and Phytochemistry, 6(4): 564-566.

Sumanth, V., Suresh, B. G., Jalandhar, B. R. and Srujana, G., 2017, Estimation of genetic variability, heritability and genetic advance for grain yield components in rice (Oryza sativa L.)

Tiwari, R., Suresh, B. G., Mishra, V. K., Kumar, A. and Kumar Ashok. 2011, Genetic variability and character association in direct seeded upland rice (Oryza sativa L.). Environment and Ecology. 29(4A): 2132-2135.

Vaithiyalingan, M. and Nadarajan, N., 2006, Genetic variability, heritability and genetic advance in rice. Crop Res., 31(3): 416-417.

Vivek, S., Surendra, S., Singh, S. K., Singh, H., Shukla, V. and Singh, S., 2004, Analysis of variability and heritability in new plant type tropical Japonica rice (Oryza sativa L.). Env. and Ecology, 22(1): 43-45.

\section{How to cite this article:}

Basavaraj S. Kovi, J.R. Diwan, K. Mahantashivayogayya, R. Lokesha, T.C. Suma and Ramesha, M.S. 2017. Genetic Investigation of BPT-5204 Derived Rice (Oryza sativa L.) Genotypes for Yield and Yield Attributed Characters under Direct Seeded Condition. Int.J.Curr.Microbiol.App.Sci. 6(12): 2294-2302. doi: https://doi.org/10.20546/ijcmas.2017.612.264 